\title{
p53 restoration can overcome cisplatin resistance through inhibition of Akt as well as induction of Bax
}

\author{
CHAE WON KIM $^{1 *}$, JING NAN LU ${ }^{2,5^{*}}$, SE-IL GO ${ }^{2}$, JI HYUN JUNG ${ }^{2}$, SANG MI YI $^{2}$, JAE-HOON JEONG ${ }^{3}$, \\ YOUNG-SOOL HAH ${ }^{2}$, MYUNG SHIN HAN ${ }^{1}$, JEONG WOO PARK ${ }^{1}$, WON SUP LEE ${ }^{2}$ and YOUNG JOO MIN ${ }^{4}$ \\ ${ }^{1}$ Department of Biological Sciences, University of Ulsan, Ulsan; ${ }^{2}$ Department of Internal Medicine, \\ Institute of Health Sciences, Gyeongsang National University School of Medicine, Gyeongnam Regional Cancer Center, \\ Gyeongsang National University Hospital, Jinju; ${ }^{3}$ Research Center for Radiotherapy, Korea Institute of Radiological \\ and Medical Sciences, Seoul; ${ }^{4}$ Department of Internal Medicine, Ulsan University Hospital, \\ University of Ulsan College of Medicine, Ulsan, Republic of Korea
}

Received June 19, 2013; Accepted July 24, 2013

DOI: 10.3892/ijo.2013.2070

\begin{abstract}
Cisplatin (CDDP) is a chemotherapeutic agent that is widely used to treat many cancers. However, initial resistance to CDDP is a serious problem in treating cancers. In this study, in order to develop an approach to overcome resistance to CDDP, we investigated the difference in apoptotic processes between CDDP-sensitive cells and CDDP-resistant cells. By screening with CDDP sensitivity tests, we chose SNU-16 cells which are relatively resistant to CDDP, and SNU-1 cells which are sensitive to CDDP. We compared the difference between the two cell lines focusing on apoptosis. CDDP-induced reactive oxygen species (ROS) generation significantly induced loss of mitochondrial membrane potential (MMP, $\Delta \Psi_{m}$ ) in SNU-1 cells, but not in SNU-16 cells. In addition, the ratio of Bax to Bcl-2 was increased by CDDP treatment in SNU-1 cells, but not in SNU-16 cells. To augment the loss of MMP, $\Delta \Psi_{m}$ in SNU-16, we inhibited Akt activity of SNU-16 cells to suppress their anti-apoptotic activity. The inhibition of Akt activity led to suppression of the anti-apoptotic protein XIAP. Akt inhibition
\end{abstract}

Correspondence to: Professor Won Sup Lee, Department of Internal Medicine, Institute of Health Sciences, Gyeongsang National University School of Medicine, 90 Chilam-dong, Jinju 660-702, Republic of Korea

E-mail: lwshmo@hanmail.net; lwshmo@gshp.gsnu.ac.kr

Professor Young Joo Min, Department of Internal Medicine, Ulsan University Hospital, University of Ulsan College of Medicine, Ulsan, Republic of Korea

E-mail: yjmin@uuh.ulsan.kr

Present address: ${ }^{5}$ The 5th Hospital of Shijiazhuang, Shijizhuang 050021, P.R. China

*Contributed equally

Key words: cisplatin, resistance, apoptosis, p53, gastric cancer slightly enhanced CDDP-induced apoptosis in SNU-16 cells. In addition, we enhanced pro-apoptotic activity by transfecting the cells with the wild-type p53 gene. The induction of wild-type p53 can enhance CDDP-induced apoptosis not only by inducing Bax protein but also by suppressing anti-apoptotic proteins through inhibition of Akt. In conclusion, this study suggests that the primary contributor to resistance to CDDP in SNU-16 cells may well be a failure of induction of apoptosis due to a lack of induction of pro-apoptotic proteins rather than suppression of anti-apoptotic proteins, and that restoration of p53 function can overcome the resistance to CDDP not only by augmenting the pro-apoptotic drive through p53-mediated transcriptional activation but also by inhibiting the anti-apoptotic drive through inhibition of Akt activity.

\section{Introduction}

Cisplatin (CDDP, cis-diaminedichloroplatinum) is a widely used chemotherapeutic agent for the management of gastric cancers. Resistance to CDDP based chemotherapy is a major cause of treatment failure. Chemotherapy resistance is a multifactorial phenomenon of the molecular mechanisms, many of which are poorly understood. One mechanism of resistance may be mediated through enhanced anti-apoptotic activity (1). In general, the target for CDDP is DNA, to which it binds efficiently to form a variety of monoadducts and cross links, either between adjacent bases on the same strand of DNA or on opposing strands $(2,3)$. These DNA lesions contribute to the cytotoxicity of CDDP through blocking DNA replication and stimulating signals for apoptosis (4). In the CDDP-induced apoptosis, mitochondria play an important role. CDDP can induce MMP $\left(\Delta \Psi_{m}\right)$, which leads to cytochrome $c$ release to the cytoplasm and subsequent activation of caspases $(5,6)$. In this process, pro-apoptotic and anti-apoptotic proteins serve as determinants of the cell fate. In the induction of pro-apoptotic proteins by DNA-damage-induced signaling, the role of tumor suppressor p53 is indisputable. Upregulation of proapoptotic proteins such as Bax and PUMA is mediated by post-translational modifications, such as phosphorylation and acetylation of the $\mathrm{p} 53$ protein. 
However, the wild-type p53 alone is not a direct predictor of the chemotherapeutic response (6). Regarding CDDP resistance, activation of the phosphatidylinositol-3-kinase/Akt pathway also plays an important role in chemotherapy resistance by inducing anti-apoptotic proteins. We are still confronting this resistance problem in treating cancer patients even though much effort has been devoted to solve it. In this study, we screen the sensitivity of cancer cells to CDDP and then looked into the CDDP-induced apoptotic process to investigate CDDP resistance.

\section{Materials and methods}

Cell line and cell culture. Three of the gastric cancer cell lines, SNU-1, SNU-5, SNU-16 cells were obtained from the Laboratory of Cell Biology at the Cancer Research Institute in Seoul National University College of Medicine. They were cultured in RPMI-1640 supplemented with 10\% FBS (Gibco-BRL, Carlsbad, CA, USA), 100 units of penicillin and $100 \mu \mathrm{g} / \mathrm{ml}$ of streptomycin at $37^{\circ} \mathrm{C}$ in the humidified atmosphere of $95 \%$ air and $5 \% \mathrm{CO}_{2}$ in an incubator. Molecular mass markers for proteins were obtained from Pharmacia Biotech (Saclay, France). Antibodies against phospho-Akt (Ser473), Akt 1/2/3, XIAP, Bcl-2 (N-19), p53, phospho-p70 S6 kinase $\alpha$ (Thr389), and GFP were purchased from Santa Cruz Biotechnology Inc. (Santa Cruz, CA, USA). Antibodies against phospho-Akt (Thr308), and phospho-p53 (ser15) were purchased from Cell Signaling Technology Inc. (Beverly, MA, USA). Antibody against $\beta$-actin was from Sigma (Beverly, MA, USA). Peroxidase-labeled donkey anti-rabbit and sheep anti-mouse immunoglobulin, and an enhanced chemiluminescence (ECL) kit were purchased from Amersham (Arlington Heights, IL, USA). All other chemicals not specifically cited here were purchased from Sigma Chemical Co. (St. Louis, MO, USA).

TdT-mediated dUTP nick end labeling staining. TdT-mediated dUTP nick end labeling (TUNEL) staining was conducted using an in situ cell death detection kit, TMR Red, according to the protocol supplied by the manufacturer (Roche Molecular Biochemicals, Mannheim, Germany). Briefly, cells were plated in $25-\mathrm{cm}^{2}$ flasks at a density of $2 \times 10^{5}$ cells $/ \mathrm{ml}$. The following day cells were treated with $0-50 \mu \mathrm{g} / \mathrm{ml}$ of CDDP, harvested and fixed with $2 \%$ paraformaldehyde solution and permeabilized with $0.1 \%$ Triton $\mathrm{X}-100$ in $0.1 \%$ sodium citrate. After washing twice with PBS, cells were incubated in a TUNEL reaction mixture containing terminal deoxynucleotidyl transferase and tetramethyl-rhodamine-dUTP. Cells were analyzed for fluorescence intensity using a FACS flow cytometer (Becton-Dickinson, Mountain View, CA, USA). When necessary, pan caspase inhibitor z-VAD-fmk (0-100 $\mu \mathrm{g} / \mathrm{ml})$, caspase-3/7 inhibitor $(0-100 \mu \mathrm{g} / \mathrm{ml})$, caspase-9 inhibitor $(0-100 \mu \mathrm{g} / \mathrm{ml})$, caspase- 8 inhibitor (0-100 $\mu \mathrm{g} / \mathrm{ml})$ (Calbiochem, Darmstadt, Germany) were applied $1 \mathrm{~h}$ prior to CDDP treatment and were kept in the medium until the cells were analyzed.

Cell line selection. The relative CDDP cytotoxicity of the three cell lines was evaluated using an MTT colorimetric assay. Briefly, SNU-1, SNU-5 and SNU-16 cells were plated in triplicate at $1.2 \times 10^{4}$ cells/well in 96 -well culture plates with RPMI-1640. The following day, the cells were treated with
CDDP at concentrations ranging from 0-50 $\mu \mathrm{g} / \mathrm{ml}$. Following treatment, cell viability was determined by MTT assays. Absorbance at $600 \mathrm{~nm}$ (OD600) was determined for each well using an ELX 808 automated microplate reader (Bio-Tek Instrument Inc., Winooski, VT, USA).

Measurement of mitochondrial membrane potential (MMP, $\left.\Delta \Psi_{m}\right)$ and reactive oxygen species generation. Cells $\left(5 \times 10^{5} / \mathrm{ml}\right)$ were exposed to $12 \mu \mathrm{g} / \mathrm{ml}$ of CDDP for $20 \mathrm{~h}$. ROS scavenger $\mathrm{N}$-acetyl-L-cysteine (NAC) $(0.5 \mathrm{mM})$ (Sigma Chemical Co.) was applied $1 \mathrm{~h}$ prior to CDDP treatment, and the cells were kept in the medium until they were analyzed. The cells were then washed with PBS and harvested by trypsinization. Early apoptosis was detected by Annexin V stain and measured using a FACS flow cytometer (Becton-Dickinson, San Jose, CA, USA). SNU-1 and SNU-16 cells were treated with the same condition with CDDP. After exposure to CDDP, the cells were incubated with $10 \mu \mathrm{M}$ 2',7'-dichlorofluorescein diacetate (DCF-DA) for ROS levels and $30 \mathrm{nM}$ 3',3'-dihexyloxacarboxyanine iodide $\left[\mathrm{DiOC}_{6}(3)\right]$ (Sigma Chemical Co.) for $\operatorname{MMP}\left(\Delta \Psi_{m}\right)$ at $37^{\circ} \mathrm{C}$ for $30 \mathrm{~min}$. The cells were then washed with ice-cold PBS and harvested by trypsinization. Fluorescence was determined using a FACS flow cytometer.

Western blot analysis. Cells were washed twice with cold PBS, and total cell lysates were obtained using lysis buffer containing $0.5 \%$ SDS, $1 \%$ NP-40, $1 \%$ sodium deoxycholate, $150 \mathrm{mM} \mathrm{NaCl}, 50 \mathrm{mM}$ Tris- $\mathrm{Cl}(\mathrm{pH} 7.5)$, and protease inhibitors. The concentrations of cell lysate proteins were determined by means of the Bradford protein assay (Bio-Rad Laboratories, Richmond, CA, USA) using bovine serum albumin as the standard. Molecular mass markers for proteins were obtained from Pharmacia Biotech. For western blot analysis, protein (30 $\mu \mathrm{g})$ was resolved by electrophoresis, electrotransferred to polyvinylidene difluoride membranes (Millipore, Bedford, MA, USA), and then incubated with primary antibodies followed by incubation with a secondary antibody conjugated to peroxidase. Blots were developed with an ECL detection system. Autoradiography film was exposed at multiple time points to obtain the best images.

\section{Results}

$S N U-16$ cells are relatively resistant to $C D D P$ whereas $S N U-1$ cells are sensitive and the difference is derived from the difference in apoptosis. To investigate CDDP-induced apoptosis in gastric cancer cells, we examined the CDDP sensitivity through MTT assay of the three cell lines (SNU-1, SNU-5, SNU-16 cells). As shown in Fig. 1A and B, the growth of the three cell lines was inhibited by CDDP treatment in a dosedependent manner, and $\mathrm{IC}_{50}$ for the $24 \mathrm{~h}$ CDDP treatment was less than $10 \mu \mathrm{g} / \mathrm{ml}$ in SNU-1 cells whereas in SNU-16 cells $\mathrm{IC}_{50}$ was greater than $20 \mu \mathrm{g} / \mathrm{ml}$. SNU-16 was the most resistant to CDDP. To determine whether the decrease in viability was related to apoptosis, we performed a TUNEL assay. The discrepancy in the degree of apoptosis became apparent after $12 \mathrm{~h}$ of treatment (Fig. 1C). These findings suggest that SNU-16 cells are relatively resistant to CDDP whereas SNU-1 cells are sensitive and that the difference is derived from the difference in apoptosis between the two cell lines. 

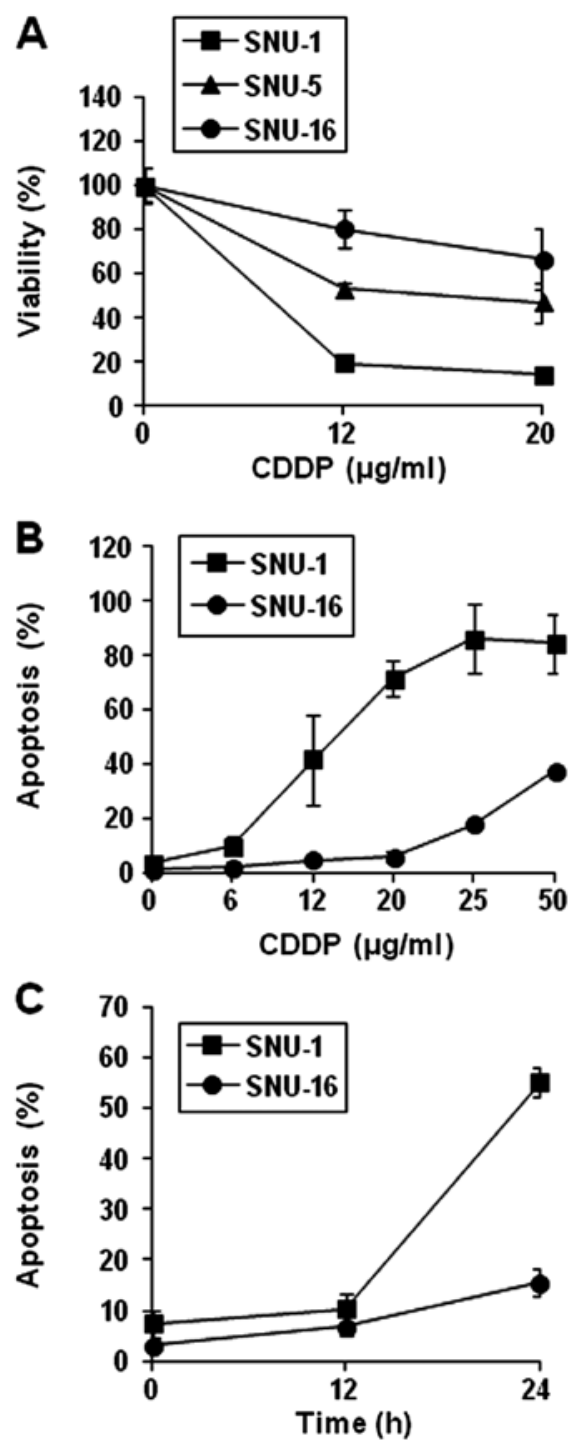

Figure 1. Difference in sensitivity to CDDP between SNU-1 and SNU-16 cells. (A) Viability determined by MTT assay. SNU-1, SNU-5, SNU-16 cells were seeded at $1 \times 10^{5}$ cells $/ \mathrm{ml}$ and then treated with the indicated concentrations of CDDP for $24 \mathrm{~h}$. (B and C) To compare the degree of apoptosis between SNU-1 and SNU-16 cells, TUNEL analysis was performed. SNU-1, SNU-16 cells were seeded at $1 \times 10^{5}$ cells $/ \mathrm{ml}$ and then treated with the indicated concentrations of CDDP for $24 \mathrm{~h}$. The apoptotic cells were analyzed by TUNEL staining.

CDDP treatment induces caspase-dependent apoptosis in SNU-1 cells. To confirm that CDDP-induced apoptosis was caspase-dependent, we performed MTT assay with caspase inhibitors (z-VAD-FMK, Z-LEHD-FMK, Z-IETD-FMK and Z-DEVD-FMK). The SNU-1 cells were exposed to only $12 \mu \mathrm{g} / \mathrm{ml}$ of CDDP for $20 \mathrm{~h}$ which caused $70 \%$ apoptosis in the SNU-1 cells. These inhibitors significantly suppressed the apoptosis induced by CDDP (Fig. 2). This result suggests that CDDP induced-apoptosis is caspase-dependent.

Loss of mitochondrial membrane potential [MMP $\left.\left(\Delta \Psi_{m}\right)\right]$ is critical in CDDP induced apoptosis in SNU-1 and $S N U-16$ cells. Oxidative damage plays an important role in CDDP-induced apoptosis (7). To investigate the causes of the difference in sensitivity to CDDP between SNU-1 cells and SNU-16 cells, we compared intracellular ROS level in SNU-1

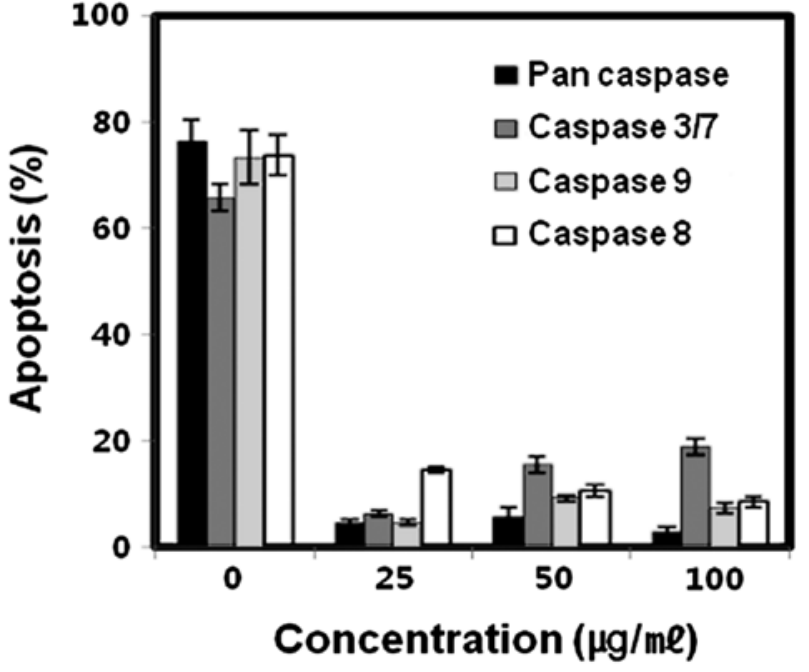

Figure 2. CDDP induces caspase-dependent apoptosis in SNU-1 cells. SNU-1 cells were treated for $20 \mathrm{~h}$ with $12 \mu \mathrm{g} / \mathrm{ml}$ of CDDP and with caspase inhibitors at increasing concentrations (pancaspase inhibitor, caspase 3/7 inhibitor, caspase 9 inhibitor, or caspase 8 inhibitor). Then, apoptotic cells were stained by TUNEL staining.

and SNU-16 cells after CDDP treatment. CDDP $(12 \mu \mathrm{g} / \mathrm{ml}$ for $20 \mathrm{~h}$ ) increased the ROS level in SNU-16 cells (data not shown). Many SNU-1 cells were dead at the time of measurement (data not shown). Hence we assessed the effects of the ROS scavenger, $\mathrm{N}$-acetyl-L-cysteine (NAC) on CDDP-treated cells. The effects were different; NAC treatment significantly reduced apoptotic cell death of SNU-1 cells, but not in SNU-16 cells (Fig. 3A). We also compared the loss of MMP $\left(\Delta \Psi_{m}\right)$ induced by CDDP between SNU-1 and SNU-16 cells. The loss of MMP level was significantly higher in SNU-1 cells than in SNU-16 cells (Fig. 3B). These findings indicated that CDDP-induced reactive oxygen species (ROS) generation significantly induced loss of MMP $\left(\Delta \Psi_{m}\right)$ in SNU-1 cells, but not in SNU-16 cells, suggesting that the loss of $\operatorname{MMP}\left(\Delta \Psi_{m}\right)$ may determine the level of apoptotic cell death.

The ratio of Bax to Bcl-2 protein is different in CDDP-induced apoptosis between $S N U-1$ and $S N U-16$ cells. We investigated further proteins regulating $\mathrm{MMP}\left(\Delta \Psi_{m}\right)$ such as Bcl-2 and Bax proteins. Western blot analysis revealed that Bax protein level of SNU-1 was significantly increased by CDDP compared to SNU-16 cells (Fig. 4A), while Bcl-2 protein expression in SNU-1 treated by CDDP was significantly suppressed compared to that in SNU-16 cells (Fig. 4B). Hence the ratio of Bax to Bcl-2 protein increased after CDDP treatment in SNU-1 cells, but not in SNU-16 cells. This result suggests that the ratio of pro-apoptotic drive to anti-apoptotic drive such as the ratio of Bax to Bcl-2 protein may determine the difference in CDDPinduced apoptosis between SNU-1 and SNU-16 cells.

CDDP increased Akt phosphorylation but the induced Akt activity did not prevent phosporylation of p53 in SNU-16 cells. Increased Akt activity promotes CDDP resistance by inhibiting pro-apoptotic drive as well as augmenting anti-apoptotic drive (8-10). First, we assessed Akt expression in SNU16 cells treated with CDDP over the time frame. Western blot analysis revealed 

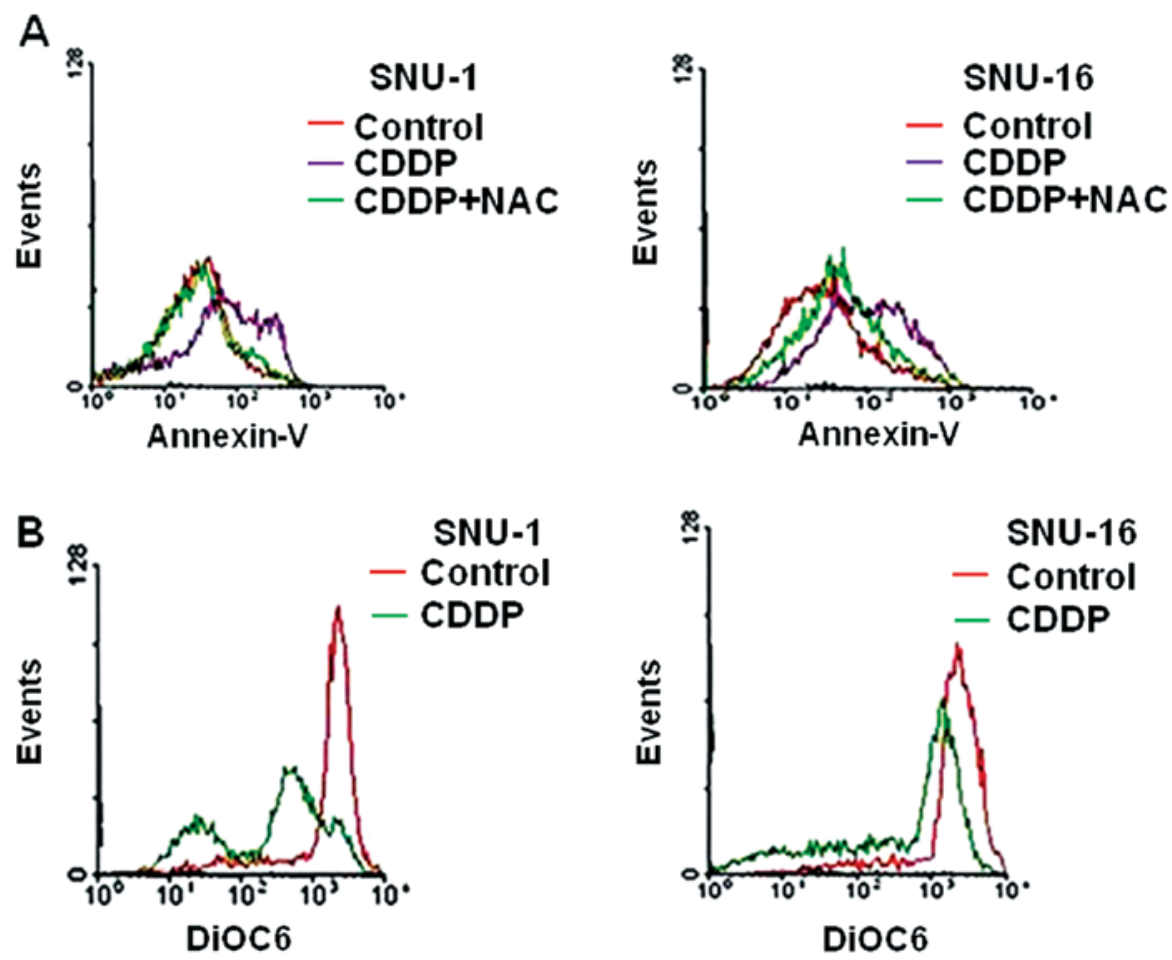

Figure 3. Loss of mitochondrial membrane potential [MMP $\left.\left(\Delta \Psi_{m}\right)\right]$ is critical in CDDP-induced apoptosis in SNU-1 and SNU-16 cells. SNU-1 and SNU-16 cells were treated with $12 \mu \mathrm{g} / \mathrm{ml}$ of CDDP for $20 \mathrm{~h}$. (A) N-acetyl-L-cysteine (NAC) $(0.5 \mathrm{mM})$ treatment was given $1 \mathrm{~h}$ before the CDDP treatment. CDDP induced apoptosis in both SNU-1 and SNU-16 cells, but the efficacies of NAC were different between the two cell lines. (B) The CDDP-induced MMP loss $\left(\Delta \Psi_{m}\right)$ was markedly greater in the SNU-1 cells than in the SNU-16 cells. Cells were treated with DiOC6 [for MMP $\left(\Delta \Psi_{m}\right)$ ] and fluorescence intensity was measured by FACS .
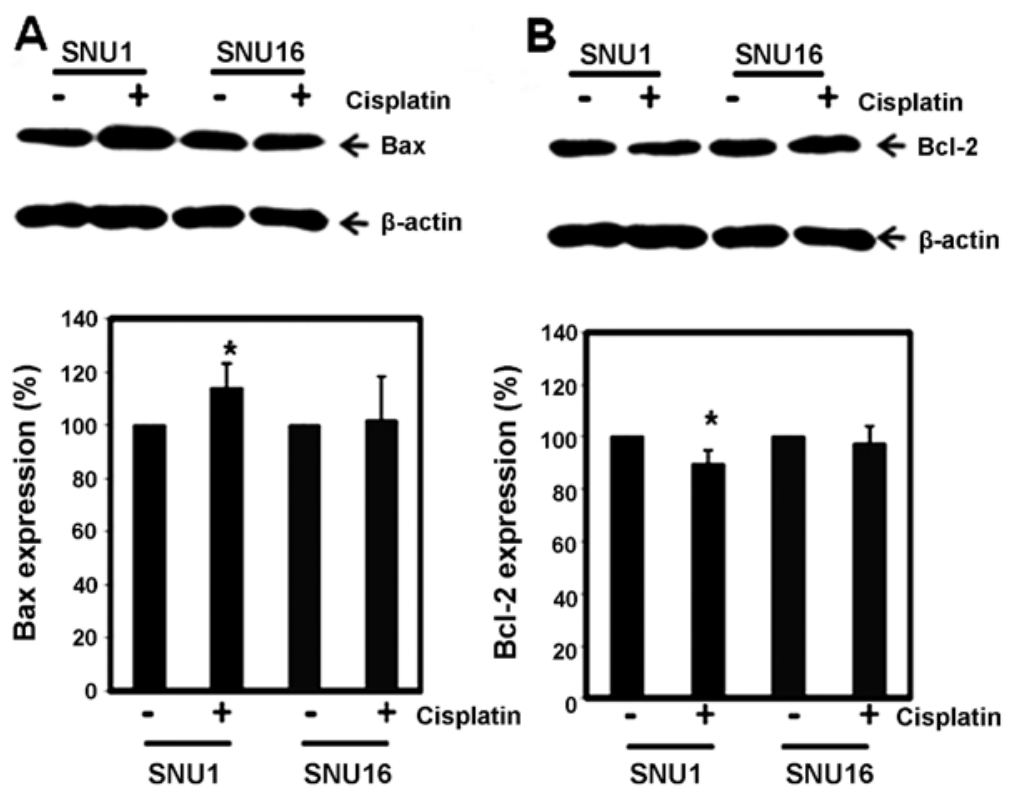

Figure 4. Induction of Bax protein is important in CDDP-induced apoptosis in SNU-1 and SNU-16 cells. Western blot analysis for the effects of CDDP on the expression of Bax and Bcl-2 in SNU-1 and SNU-16 cells. The cells were treated with $12 \mu \mathrm{g} / \mathrm{ml}$ of CDDP. Equal amounts of the cell lysate were separated by SDS-polyacrylamide gels and then transferred to nitrocellulose membranes, and probed with the indicated antibodies and detected by an ECL detection system. The expression levels of (A) BAX and (B) Bcl-2 were quantified by Image, normalized to the internal control $\beta$-actin. The expression of the indicated proteins were measured by densitometry, and the values represent means $\pm \mathrm{SD}$. ${ }^{*} \mathrm{P}<0.05$ versus control.

that CDDP increased Akt activity (Fig. 5A). Increased Akt activity promotes CDDP resistance in cancer cells through inhibition of p53 phosphorylation and transcriptional activity
(10). In p53-functioning cells, the phosphorylation of p53 has also been reported to be an independent determinant of transcriptional upregulation of pro-apoptotic proteins such as 
A
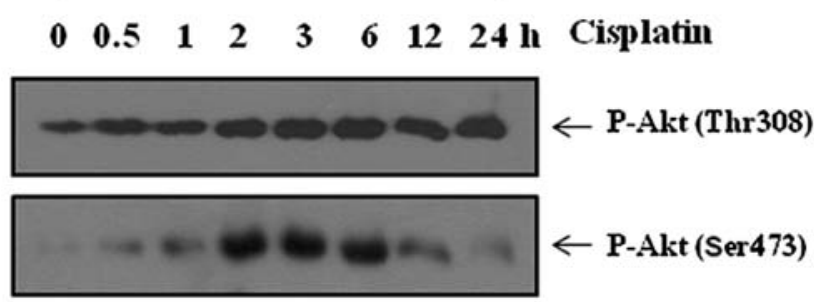

B
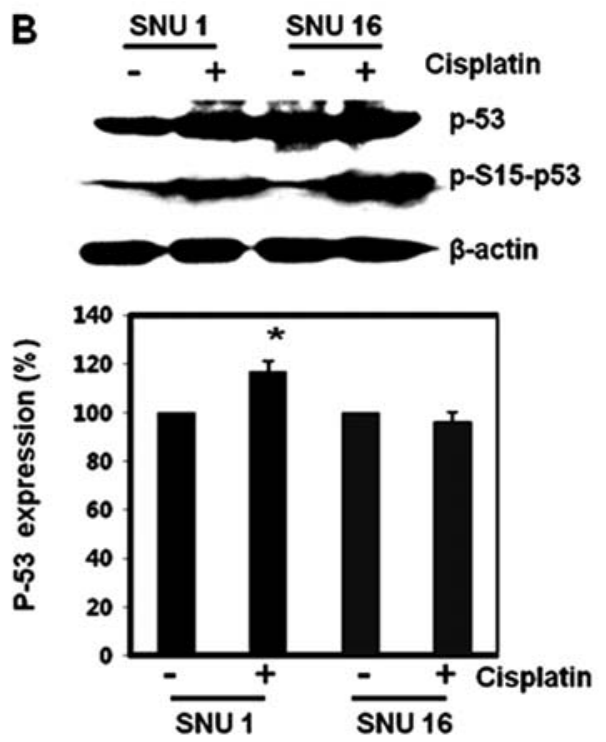

Figure 5. CDDP increased Akt phosphorylation but the induced Akt activity may not be related to phosporylation and expression of p53 in SNU-16 cells. Western blot analysis for the effects of CDDP on the activity of Akt and p53 in SNU-1 and SNU-16 cells. The cells were treated with $12 \mu \mathrm{g} / \mathrm{ml}$ of CDDP. Equal amounts of the cell lysate were separated by SDS-polyacrylamide gels and then transferred to nitrocellulose membranes and probed with the indicated antibodies and detected by an ECL detection system. (B lower panel) The expression levels of total p53 were quantified by densitometry, normalized to the internal control $\beta$-actin. The expression of the indicated proteins were measured by densitometry, and the values represent means $\pm \mathrm{SD}$. ${ }^{*} \mathrm{P}<0.05$ versus control.

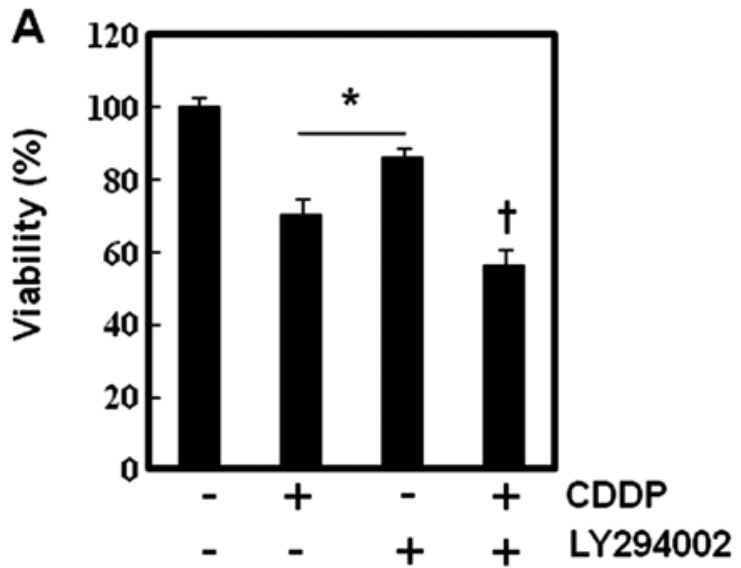

B

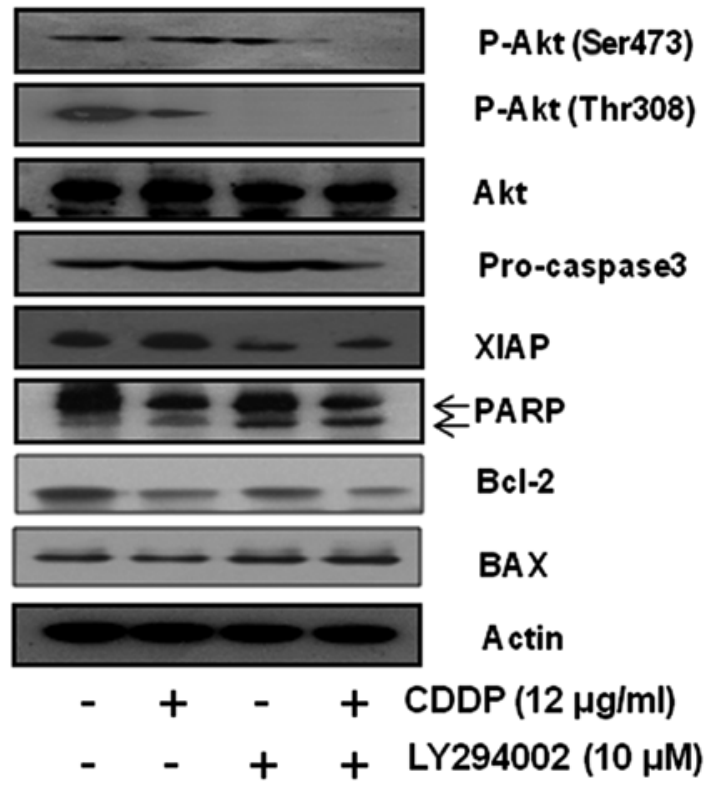

Bax and PUMA in CDDP-induced apoptosis. However, Bax proteins can be upregulated by other transcriptional factors (11). Hence, we examined the expression of p53 or p-p53 levels. CDDP increased the expression of p53 and p-p53 (Ser15) in both SNU-1 and SNU-16 cells (Fig. 5B). This result suggests that phosporylated p53 should not induce Bax protein in SNU-16 cells, which means that SNU-16 cells should be p53-mutant or p53-non-functioning cancer cells; the results also confirmed that phosporylated p53 (Ser15) is an independent determinant for CDDP-induced apoptosis only in p53 functioning cancer cells. These findings suggest that Bax induction by CDDP in SNU-1 cells may be derived from p53 activation, and that increased Akt may not significantly suppress CDDP-induced phosphorylation of p53 in SNU-16 cells.

PI3K/Akt inhibition enhanced CDDP-induced apoptosis by suppression of anti-apoptotic proteins, but the efficacy was minimal. To augment loss of MMP, $\Delta \Psi_{m}$ in SNU-16 by suppressing anti-apoptotic activity, and to investigate the role of PI3K/Akt pathway in CDDP-induced apoptosis in SNU-16 cells we inhibited the Akt activity of SNU-16 cells using LY294002, a representative PI3k/Akt inhibitor. As shown in Fig. 6, LY294002 slightly accentuated the cytotoxicity of

Figure 6. Akt pathway is not critical for the resistance of SNU-16 cells to CDDP treatment. (A) Viability determined by MTT assay. SNU-16 cells were seeded at $1 \times 10^{5}$ cells $/ \mathrm{ml}$ and then treated with LY294002 $(10 \mu \mathrm{g} / \mathrm{ml}) 1 \mathrm{~h}$ prior to the treatment with CDDP $(12 \mu \mathrm{g} / \mathrm{ml})$ for $24 \mathrm{~h}$. The values represent means \pm SD. ${ }^{*} \mathrm{P}<0.05$ versus control. (B) Western blot analysis of the effects of LY294002 on CDDP-induced cell death in SNU-16 cells. The cells were treated according to the above time schedule. Equal amounts of the cell lysate were separated by SDS-polyacrylamide gels and then transferred to nitrocellulose membranes and probed with the indicated antibodies and detected by an ECL detection system. 
A

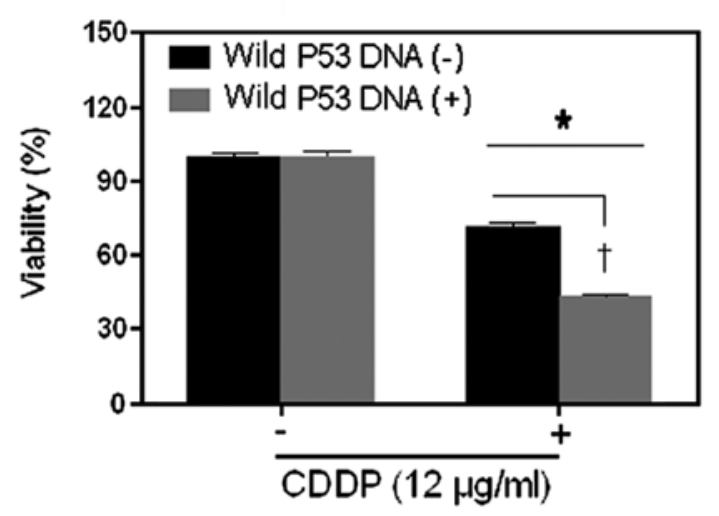

B

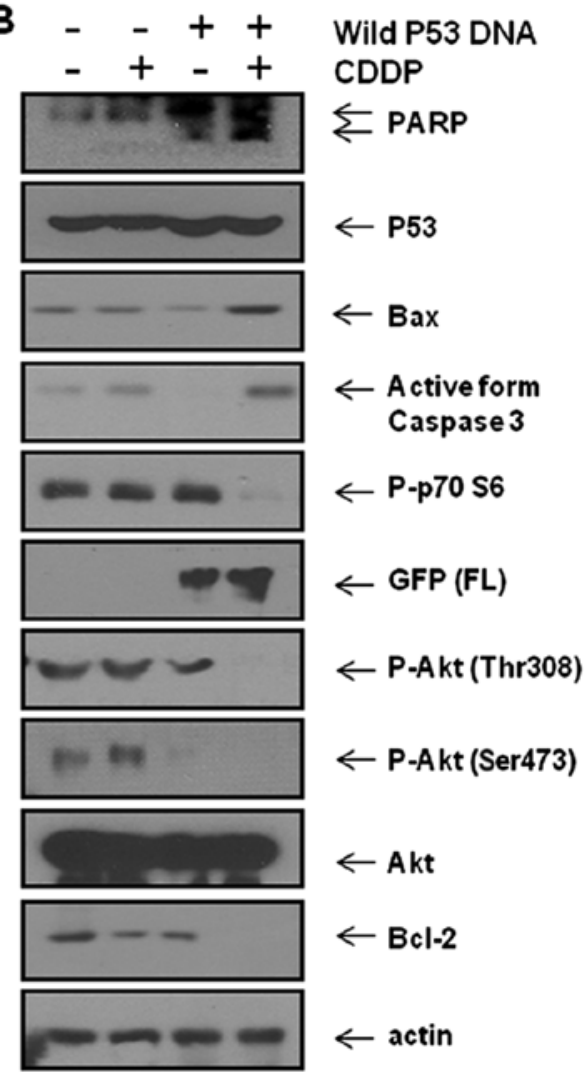

Figure 7. The resistance to CDDP of SNU-16 cells can be overcome by p53 augmentation through inhibition of Akt as well as induction of Bax. (A) Viability determined by MTT assay. SNU-16 cells were transiently transfected with $\mathrm{p} 53$ expression vector or empty vector for $24 \mathrm{~h}$ and then treated with CDDP $(12 \mu \mathrm{g} / \mathrm{ml})$ for $24 \mathrm{~h}$. The values represent means $\pm \mathrm{SD}$. ${ }^{*} \mathrm{P}<0.05$ versus CDDP-free. ${ }^{\dagger} \mathrm{P}<0.05$ versus empty vector. (B) Western blot analysis for the effects of wild-type p53 on CDDP-induced cell death in SNU-16 cells. The cells were treated under the above time schedule. Equal amounts of the cell lysate were separated by SDS-polyacrylamide gels and then transferred to nitrocellulose membranes and probed with the indicated antibodies and detected by an ECL detection system.

CDDP in MMT assay and no synergism was observed between LY294002 (PI3k/Akt inhibitor) and CDDP in SNU-16 cells. To confirm this finding at the molecular level, we performed western blot analysis for apoptosis-related factors and p-Akt. The suppression of Akt phosphorylation led to inhibition of XIAP and activation of apoptosis-related enzyme (PARP and caspase 3). We found that LY294002 enhanced the cytotoxicity of CDDP by suppressing XIAP. This result suggests that inhibition of Akt may not significantly enhance the sensitivity of CDDP in SNU-16 cells even though CDDP induces Akt activation.

The resistance to CDDP of SNU-16 cells can be overcome by 553 augmentation through inhibition of Akt as well as induction of Bax. We assumed that the reason why PI3k/Akt inhibitor did not induce synergism with CDDP is the lack of the proapoptotic drive due to loss of p53 function. Therefore, we transfected SNU-16 cells with wild-type p53, and then tested the sensitivity to CDDP. MTT assay revealed that in the SNU-16 cells transfected with wild-type p53, the sensitivity to CDDP was significantly enhanced (Fig. 6A). To confirm this finding at the molecular level, we performed western blot analysis for p53 and downstream molecules of PI3k/Akt pathway. Successful transfection with wild-type p53 was confirmed with GFP. Interestingly, the transfection of wild-type p53 alone did not significantly influence phosphorylation of
p70S6K, or of Akt as well as Bax induction. However, addition of CDDP on the p53-trasfected cells not only augmented Bax induction but also suppressed Bcl-2 through inhibition of Akt phosphorylation. These results suggest that restoration of $\mathrm{p} 53$ function can overcome the resistance to CDDP by augmenting the proapoptotic drive through $\mathrm{p} 53$-mediated transcriptional activation and by inhibiting the anti-apoptotic drive through inhibition of Akt activity (Figs. 7 and 8).

\section{Discussion}

Our study was designed to demonstrate the difference in apoptotic processes in CDDP-induced apoptosis between constitutively CDDP-sensitive and CDDP-resistant gastric cancer cells in vitro, and to find a method to overcome the resistance to CDDP. SNU-16 cells are the most resistant to CDDP and SNU-1 the most sensitive among the 3 cell lines (SNU-1, SNU-5 and SNU-16). The major contributor to the big difference in CDDP-induced cell death between SNU-1 cells and SNU-16 cells was loss of MMP $\left(\Delta \Psi_{m}\right)$. The loss of $\operatorname{MMP}\left(\Delta \Psi_{m}\right)$ is one of the main events of the apoptotic process induced by chemotherapeutic drugs $(12,13)$, and this results in either caspase-dependent or independent apoptosis $(14,15)$. In this study, significant loss of MMP $\left(\Delta \Psi_{m}\right)$ by CDDP treatment was observed in SNU-1 cells, but not in SNU-16 cells. This finding indicates that lack of the proapoptotic drive or a 


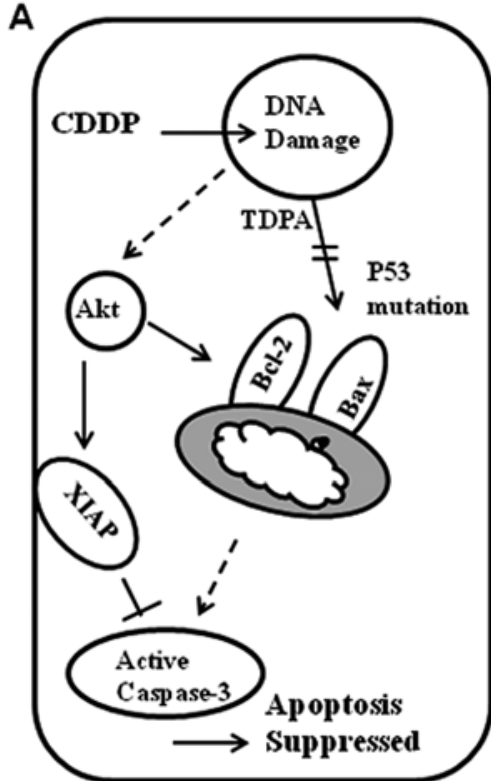

Cisplatin alone

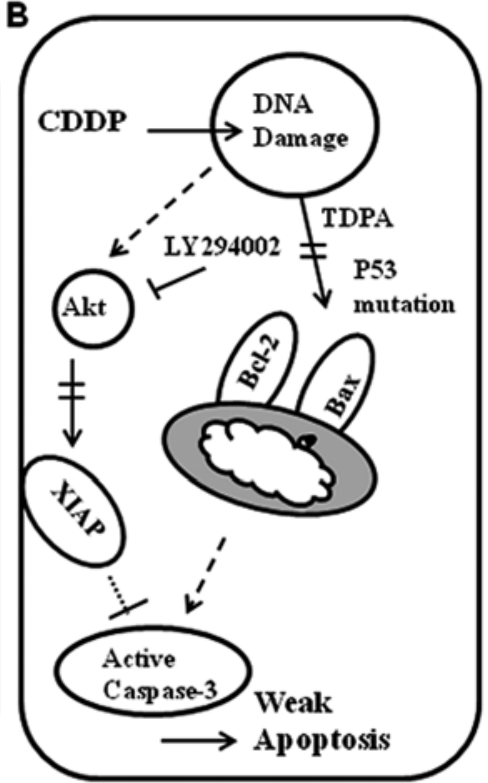

Cisplatin+LY294002

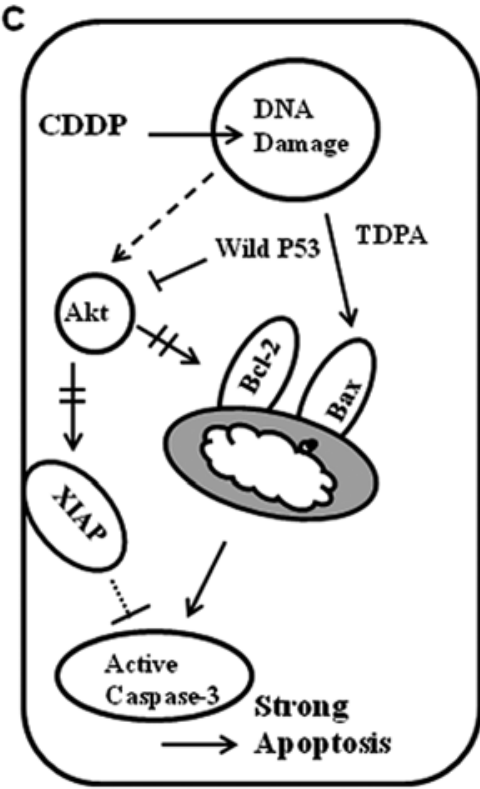

Cisplatin- Wild p53 DNA

\section{CDDP-resistant SNU 16 Human Gastric Carcinoma Cells}

Figure 8. Schematic representation of CDDP-induced apoptosis in SNU 16 human gastric carcinoma cells. (A) SNU-16 cells showed resistance to CDDP treatment due to increased Akt activity as well as p53 mutation. Increased Akt induced XIAP. (B) Inhibition of Akt by LY294002 enhanced the cytotoxicity of CDDP by suppressing XIAP in p53 mutant SNU-16 cells, but the efficacy was minimal due to lack of apoptotic drive. (C) When we restored p53 gene function by transfecting wild type p53 gene into SNU16 cells, the wild type p53 can enhance CDDP-induced apoptosis by induction of Bax as well as suppression of anti-apoptotic proteins through the inhibition of Akt in SNU-16 cells. Taken together, this study suggests that the restoration of p53 is still critical in CDDP-induced apoptosis in p53 mutant SNU-16 human gastric cancer cells.

surplus of anti-apoptotic drive induced the failure of CDDP in inducing loss of MMP $\left(\Delta \Psi_{m}\right)$ in SNU-16 cells. Our data indicated that SNU-16 cells were p53-non-functioning cells. Actually, SNU-16 cells have a missense mutation of codon 205, TAT to TTT, Tyr to Phe (16). This area belongs to the p53 DNA binding domain (17). This is consistent with our findings. Here, we also tested whether an Akt inhibitor can enhance the CDDP sensitivity in p53 mutation cancer cells by suppressing the anti-apoptotic proteins because a previous study suggested that the mutation status of p53 might not predict the chemo-response, and that Akt activation might be involved in CDDP resistance. Unlike the previous report, inhibition of PI3K/Akt pathway was not adequate to overcome CDDP resistance in SNU-16 cells. We also tested whether the anthocyanins enhanced CDDP sensitivity, because it has been reported that anthocyanins isolated from Vitis coignetiae Pulliat can enhance apoptosis by suppressing anti-apoptotic proteins such as Bcl-2, and XIAP through the inhibition of Akt and $N F-\kappa B$ that are involved in drug resistance $(18,19)$. Similar to the results of LY294002, the anthocyanins also slightly enhanced the CDDP sensitivity of SNU 16 cells, but they did not show a clear synergism (data not shown).

Here, we demonstrated that the restoration of p53 functions in SNU-16 cells enhancing CDDP-induced apoptosis not only by inducing apoptotic factors through p53-mediated transcriptional activation but also by inhibiting anti-apoptotic proteins through inhibition of Akt activity. This finding was also observed in wild-type SNU-1 cells (Fig. 4); CDDP not only augmented Bax expression but also suppressed Bcl-2 expression in SNU-1 cells. This can be explained by previous studies that suggested that DNA damage can activate pTEN through p53 activation followed by inhibition of Akt $(20,21)$. Our data encourage the use of gene therapy with wild-type p53 in cancer treatment. This result is supported by the successful results of p53 gene therapy in combination with CDDP in in vitro and xenograft cancer models, and in the patients with small cell lung cancer $(22,23)$. However, there is still controversy surrounding p53 gene therapy because there are also negative results showing no additional benefit with combination therapy (24).

The limitation of this study is that we only compared three gastric cell lines and validated the role of p53 restoration only in SNU-16 cells. In addition, there may be many other ways to enhance CDDP sensitivity. Therefore, these issues will require investigation. To reveal the clinical significance, an in vivo study followed by a clinical trial is warranted. In conclusion, this study suggests that the primary contributor to resistance to CDDP in SNU-16 cells may well be a failure of induction of apoptosis due to lack of induction of proapoptotic activities rather than an increase in anti-apoptotic activity, and that restoration of $\mathrm{p} 53$ function can overcome the resistance to CDDP not only by augmenting the proapoptotic drive through p53-mediated transcriptional activation but also by inhibiting the anti-apoptotic drive through inhibition of Akt activity. This study supports that the restoration of p53 is still important in CDDP-induced apoptosis in p53 mutant SNU-16 human gastric cancer cells. 


\section{Acknowledgements}

This study was supported by a grant from the National R\&D Program for Cancer Control, Ministry for Health, Welfare and Family Affairs, Republic of Korea (0820050), and from Priority Research Center Program through the National Research Foundation of Korea (NRF) funded by the Ministry of Education, Science and Technology (2010-0029621).

\section{References}

1. Li J, Feng Q, Kim JM, Schneiderman D, Liston P, Li M, Vanderhyden B, Faught W, Fung MF, Senterman M, Korneluk RG and Tsang BK: Human ovarian cancer and cisplatin resistance: possible role of inhibitor of apoptosis proteins. Endocrinology 142: 370-380, 2001.

2. Zwelling LA, Anderson T and Kohn KW: DNA-protein and DNA interstrand cross-linking by cis- and trans-platinum(II) diamminedichloride in L1210 mouse leukemia cells and relation to cytotoxicity. Cancer Res 39: 365-369, 1979.

3. Fichtinger-Schepman AM, van der Veer JL, den Hartog JH, Lohman PH and Reedijk J: Adducts of the antitumor drug cis-diamminedichloroplatinum(II) with DNA: formation, identification, and quantitation. Biochemistry 24: 707-713, 1985.

4. Bottone MG, Soldani C, Veneroni P, Avella D, Pisu M and Bernocchi G: Cell proliferation, apoptosis and mitochondrial damage in rat B50 neuronal cells after cisplatin treatment. Cell Prolif 41: 506-520, 2008.

5. Melendez-Zajgla J, Cruz E, Maldonado V and Espinoza AM: Mitochondrial changes during the apoptotic process of HeLa cells exposed to cisplatin. Biochem Mol Biol Int 47: 765-771, 1999.

6. Henkels KM and Turchi JJ: Cisplatin-induced apoptosis proceeds by caspase-3-dependent and -independent pathways in cisplatin-resistant and -sensitive human ovarian cancer cell lines. Cancer Res 59: 3077-3083, 1999.

7. Miyajima A, Nakashima J, Yoshioka K, Tachibana M, Tazaki H and Murai M: Role of reactive oxygen species in cis-dichlorodiammineplatinum-induced cytotoxicity on bladder cancer cells Br J Cancer 76: 206-210, 1997.

8. Pugazhenthi S, Nesterova A, Sable C, Heidenreich KA, Boxer LM, Heasley LE and Reusch JE: Akt/protein kinase B up-regulates $\mathrm{Bcl}-2$ expression through cAMP-response element-binding protein. J Biol Chem 275: 10761-10766, 2000.

9. Mitsiades CS, Mitsiades N, Poulaki V, Schlossman R, Akiyama M, Chauhan D, Hideshima T, Treon SP, Munshi NC, Richardson PG and Anderson KC: Activation of NF-kappaB and upregulation of intracellular anti-apoptotic proteins via the IGF-1/Akt signaling in human multiple myeloma cells: therapeutic implications. Oncogene 21: 5673-5683, 2002.
10. Fraser M, Bai $\mathrm{T}$ and Tsang BK: Akt promotes cisplatin resistance in human ovarian cancer cells through inhibition of p53 phosphorylation and nuclear function. Int J Cancer 122: 534-546, 2008.

11. Chipuk JE and Green DR: Dissecting p53-dependent apoptosis. Cell Death Differ 13: 994-1002, 2006.

12. Green DR and Reed JC: Mitochondria and apoptosis. Science 281: 1309-1312, 1998.

13. Crompton M: The mitochondrial permeability transition pore and its role in cell death. Biochem J 341: 233-249, 1999.

14. Gross A, McDonnell JM and Korsmeyer SJ: BCL-2 family members and the mitochondria in apoptosis. Genes Dev 13: 1899-1911, 1999.

15. Zamzami $\mathrm{N}$ and Kroemer G: The mitochondrion in apoptosis: how Pandora's box opens. Nat Rev Mol Cell Biol 2: 67-71, 2001.

16. Ku JL and Park JG: Biology of SNU cell lines. Cancer Res Treat 37: 1-19, 2005.

17. Somasundaram K: Tumor suppressor p53: regulation and function. Front Biosci 5: D424-D437, 2000.

18. Shin DY, Lee WS, Lu JN, Kang MH, Ryu CH, Kim GY, Kang HS, Shin SC and Choi YH: Induction of apoptosis in human colon cancer HCT-116 cells by anthocyanins through suppression of Akt and activation of p38-MAPK. Int J Oncol 35: 1499-1504, 2009.

19. Yun JW, Lee WS, Kim MJ, Lu JN, Kang MH, Kim HG, Kim DC, Choi EJ, Choi JY, Lee YK, Ryu CH, Kim G, Choi YH, Park OJ and Shin SC: Characterization of a profile of the anthocyanins isolated from Vitis coignetiae Pulliat and their anti-invasive activity on HT-29 human colon cancer cells. Food Chem Toxicol 48: 903-909, 2010.

20. Stambolic V, MacPherson D, Sas D, Lin Y, Snow B, Jang Y, Benchimol S and Mak TW: Regulation of PTEN transcription by p53. Mol Cell 8: 317-325, 2001.

21. Feng Z: p53 regulation of the IGF-1/AKT/mTOR pathways and the endosomal compartment. Cold Spring Harb Perspect Biol 2: a001057, 2010.

22. Wang WD, Li R, Chen ZT, Li DZ, Duan YZ and Cao ZH: Cisplatin-controlled p53 gene therapy for human non-small cell lung cancer xenografts in athymic nude mice via the CArG elements. Cancer Sci 96: 706-712, 2005.

23. Antonia SJ, Mirza N, Fricke I, Chiappori A, Thompson P, Williams N, Bepler G, Simon G, Janssen W, Lee JH, Menander K, Chada S and Gabrilovich DI: Combination of p53 cancer vaccine with chemotherapy in patients with extensive stage small cell lung cancer. Clin Cancer Res 12: 878-887, 2006.

24. Guan YS, Liu Y, Zou Q, He Q, La Z, Yang L and Hu Y: Adenovirus-mediated wild-type p53 gene transfer in combination with bronchial arterial infusion for treatment of advanced non-small-cell lung cancer, one year follow-up. J Zhejiang Univ Sci B 10: 331-340, 2009. 